LBL -27532

DE 90000168

\title{
MATERIAL PARAMETERS IN THICK HYDROGENATED AMORPHOUS SILICON RADLATION DETECTORS
}

\author{
S. Qureshi, V. Perez-Mendez. S.N. Kaplan, I. Fujieda, G. Cho, R.A. Street** \\ Lawrence Berkeley Laboratory. University of California, Berkeley, CA 94720 \\ -Xerox Parc, Palo Alto, CA 94304
}

Transient photoconductivity measurements of besic material parameters: carrier mobility, mobility-lifetime product and the ionized dangling bond den ty of thick hydrogenated amorphous silicon datectors are presenud. We found that only a fraction ( $-30-35 \%)$ of the total defect density as messured by ESR is ionized when the detector is biased into deep depletion. The measurements on annealed samples done to relate the ionized danglins bond density and the ESR spin density also showed that this fraction $i$. about 0.3 . The time dependence of defect relaxation was found 10 be stratched exponential.

\section{DNRODUCTION}

Charge collection in hydrogenated amorphous silicon (a-Si:H) p-i-n detectors depends on various material parameters namely carrier mobility. mobility-lifetime product and the ionized dangling boad densityl. The ionized dangling bond deasity determines how rapidly the electric field falls off in the active $i$ region of the detector and, therefore, determines the thickness that can be depleted at reasonable bias without causing excessive reverse current and noise2. In this paper we present measurements of these material parameters in $27 \mu \mathrm{m}$ and thicker samples. The transient photoconductivity measurements were done using a $510 \mathrm{~nm}$ pulsed laser system with 3 ns pulse width.

\section{MEASUREMENT OF MATERIAL PARAMETERS}

Table I shows the measured parameters of interest - $\mu_{e}, \mu_{h}, \mu_{e} \tau_{e}, \mu_{h} \tau_{h}$ - and the ionized dangling bond density $\mathbf{N}_{d}$ " of various samples r:om time of. tlight experiments ${ }^{3}$. Aso shown are the ESR spin densities on some samples.

It is seen the the ionized dangling bond density values are a small fraction of the tocal spis density. This observation is corroborated by the fits to the integrated hole signal using measured values of $\mu_{h}$ and $\mu_{h} T_{h}$. Values of $\mathbf{N}_{d}$ * obtained thus are in good agreement with the values obtained from transient photoconductivity experiments. 1

The dangling bond density of a $27 \mathrm{\mu m}$ $p-i-n$ (GSI) sample with tin oxide film on the substrate was obtained from the HeteNd product which follows from the basic expressions relating the capture process with the trap limited transport in amorphous semiconductorst. An average value of $\mu_{e} \tau_{e} N_{d}=2.5 \times 10^{2}$ was adopted for this purpose.

To eliminate possible effects of

*This work was supported by the Director, Office of energy Research, Office of High Energy and Nuclear Physics, Division of High Energy Physics of the U.S. Department of Energy under contract No. DE-ACO3-76SFOOO98. 


\begin{tabular}{|c|c|c|c|c|}
\hline Trietem ( $(\mu \mathrm{n})$ & 27 & II & 41 & 2700 \\
\hline In: & $a+1=2$ & $\sqrt{n-3-2}$ & $=1-2$ & $2 \cdot 1-8$ \\
\hline$\mu e^{2} \sin ^{2}\left(v_{1}\right)$ & 1 & 4 & 0.56 & 1.2 \\
\hline$\mu_{-} \operatorname{se}_{2}\left(\mathrm{~cm}^{2} \mathrm{~N}\right)$ & $1 \times 10^{-6}$ & $1.1 \times 10^{-7}$ & $9 \times 10^{-8}$ & $1.2 \times 10^{-7}$ \\
\hline$u_{n}\left(e^{2} \mathrm{n}^{2} / v_{1}\right)$ & 0.003 & 0.003 & $<0.003$ & 0.004 \\
\hline$\mu h m_{1}\left(e \mathrm{~m}^{2} N\right)$ & $1 \times 10^{-1}$ & $2.7 \times 10^{-1}$ & $<3.8 \times 10^{-8}$ & $1.2 \times 10^{-8}$ \\
\hline$V_{d} \cdot\left(\operatorname{csm}^{-3}\right)$ & $2 \times 10^{16}$ & $6=10^{14}$ & $7810^{4}$ & $7 \times 10^{14}$ \\
\hline$N A\left(c m^{3}\right)$ & $2.6 \times 10^{13}$ & $2210^{15}$ & $2.3 \times 10^{13}$ & $2.1 \times 10^{13}$ \\
\hline$N_{0}+N_{1}$ & 316 & 306 & 296 & $33,0=0$ \\
\hline de $\left.T_{p} N_{0} \mid l / c \pi n\right)$ & $12810^{6}$ & $2.2 \times 100$ & $2,2 \times 10^{2}$ & $2.5 \times 10^{8}$ \\
\hline
\end{tabular}

TABLE !

Measured parameters of different samples. - GSI Sample, "mestimaled from $\mu_{e} T_{e} N_{d}$

impurity variations in the verious samples in relating ionized dangling bond densities and the spin densities. measurements were done on samples whose defect density was increased by heating. The initial spin density of a $27 \mathrm{\mu m} \mathrm{n-i-p} \mathrm{sample} \mathrm{before} \mathrm{heat}$ treatment was $2.6 \times 10^{15} \mathrm{~cm}^{-3}$ (ESR) and the ionized dangling bond density $8 \times 10^{14} \mathrm{~cm}^{-3}$ (TOF). A spin density of $6.5 \times 10^{15} \mathrm{~cm}^{-3}$ was measured (ESR) after heating at $300^{\circ} \mathrm{c}$; the ionized defect density was measured to be 2 $x 10^{15} \mathrm{~cm}^{-3}$. The fraction of defects ionized ( - 30\%) before and after heat treatment remained unchanged. Similar results were obtained from a sample whose defect density was increased by heat treatment to $1 \times 1016 \mathrm{~cm}^{-3}$.

\section{DEFECT RELAXATION ON ANNEALING}

The heat treated samples were annealed at $175^{\circ} \mathrm{c}$ and $225^{\circ} \mathrm{C}$ and the ionized defect density measured as a function of annealing time as shown in Fig. 1. Also shown are the defect density values derived from the measured values of $\mu_{e} t_{e}$ and $\mu_{e} \tau_{e} N_{d}=2 \times 10^{3}$ in good agreement with the average value. The relaxation time dependence is a stretched exponential of the form ${ }^{5}$

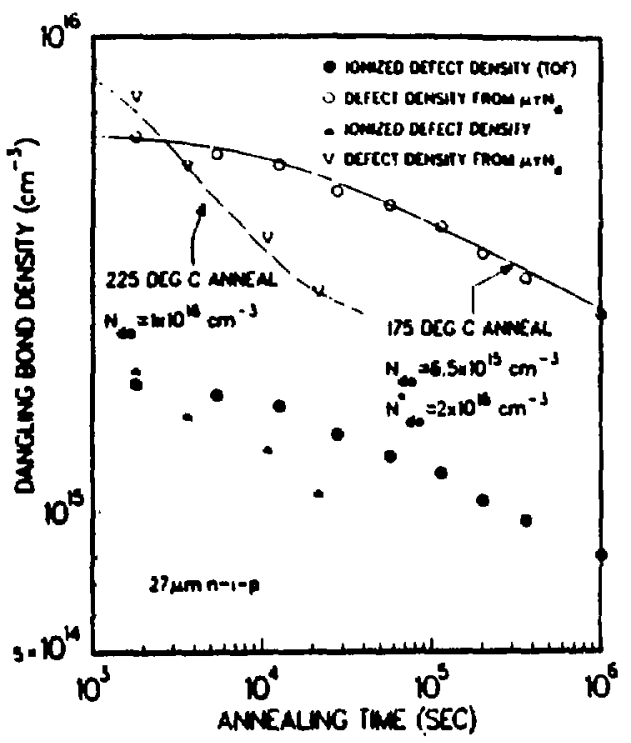

FIGURE !

lcnized defect density $\mathrm{N}_{d}$ (TOF) vs. annealing time. Also shown is defect density $N_{d}$ from $\left.{ }^{1} t_{e} \tau_{e} N_{d}=2 \times 10^{8} v^{*} c m^{-1}\right)$.

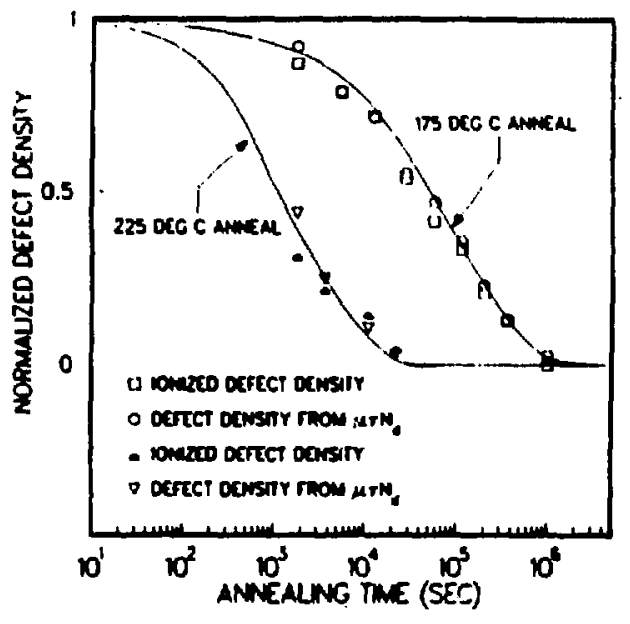

FIGURE 2

Relaxation data at $175^{\circ} \mathrm{C}$ and $225^{\circ} \mathrm{C}$. 


$$
N_{d}-N_{d e q}=N_{d o}-N_{d e q} \exp \left[-\left(t / \tau_{q}\right) \beta\right]
$$

where $N_{\text {do }}$ and $N_{\text {deq }}$ are the initial and equilibrium defect densities. $\beta$ is a dispersion parameter and $\tau$, the time required for structural relaxation. Fig. I also shows relaxation curves done at $175^{\circ} \mathrm{c}$ and $225^{\circ} \mathrm{c}$. The curves show rood agreemint with the derived values of $\mathrm{N}_{d}$. The normalized defoct density as a funst annealing time is shown in Fig. 2. . 'redn Fitit 1 and 2 it is seon that the ionized defect density as a function of annealins time also has the dependence of stretched exponential but reduced by about a factor of 3 implyins that we we looking at the same effect.

\section{IONZZED DEFECT DENSITY AND FERMI ENERGY}

Fis. 3 shows the calculated frection of ionized defects as a function of the shift of the Fermi energy. The observed ionization

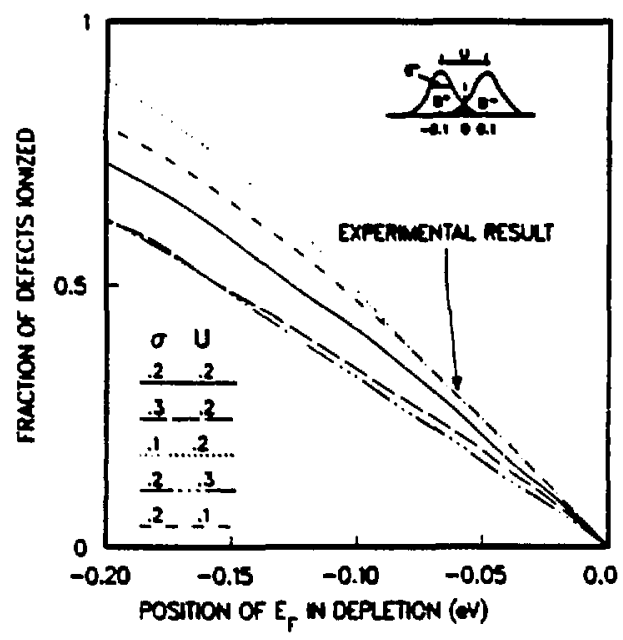

FGURE 3

Fraction of defects ionized vs. shift in Fermi enersy on depletion. fraction corresponds to a shift of the Fermi level of $0.05-0.1 \mathrm{eV}$.

\section{SUMMMARY}

Transient photoconductivity and ESR measurements made on relatively thick samples of a-Si:H show that $-30 \%$ of the defects are ionized in deep depletion. This observation is further corroborated by measurement on samples whose spin denaity was initially increased by heat treatment and reduced by subsequent annealing. It is also seen that the defect relaxation follows stretched exponential behavior and is the same for the ionized and the tocal defect density. Analysis of a simple density of states model shows that the experimentally observed ionization fraction may correspond to a shift of the Fermi energy of $0.05-0.1 \in \mathrm{V}$.

\section{ACKNOWL EDGENENT}

We would like to thank C.C. Tsai of Xerox Parc and P. Bhat of Glasstech-Solar (Whent Ridge, $\mathrm{CO}$ ) for making the samples for this work.

\section{REFERENCES}

I. S. Qureshi, ef al, IEEE Transactions on Nuclear Science, Vol 36, No. I, 194 (1989).

2. V. Perez-Meadex, of al, N.I.M., A273, No. 1 (1988) 127.

3. R.A. Street, Phys. Rev. B, 27, No.8, 4924 (1983).

4. R. A. Street, Phil. Mag. B, vol. 49 No. I, LIS. (1984); Appl. Phys. Lett 41 (11). 1060. 1982.

5. K. A. Street et al, Presented at MRS Conference, San Diezo, (April 1989). 


\section{DISCLAIMER}

This repont was prepard as an acoount of work sponcored by an asency of the Uniled Stater Covernment. Nelther the United Sinte Covernment nor any asency thereof, nor any of their

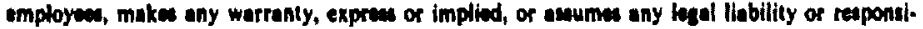
bility for the aceuracy, completenew, of usefulane of any information, apparatus, product, or procese disctond, or represents that its use would not infringe privately owned rights. Rotop: ence herein to any upecific commercial product, procaw, or service by irade name, trademart, manufecturer, of otherwixe does not mecenarily constitute or imply its endormement, recom. mendation, or favoring by the United Statea Government or any avency thereof. The viewa and opinions of authon expreased herein do not necesurily state or rellect those of the United State Government or any ateacy thereor. 